\title{
Green leafy and cruciferous vegetable consumption and risk of type 2 diabetes: results from the Singapore Chinese Health Study and meta-analysis
}

\author{
Guo-Chong Chen ${ }^{1,2}$, Woon-Puay Koh ${ }^{2,3}$, Jian-Min Yuan ${ }^{4,5}$, Li-Qiang Qin ${ }^{1}$ and Rob M. van Dam ${ }^{2,6 *}$ \\ ${ }^{1}$ Department of Nutrition and Food Hygiene, School of Public Health, Soochow University, Suzhou, 215123, People's Republic \\ of China \\ ${ }^{2}$ Saw Swee Hock School of Public Health, National University of Singapore, Singapore 117549, Singapore \\ ${ }^{3}$ Duke-NUS Medical School, Singapore 169857, Singapore \\ ${ }^{4}$ Division of Cancer Control and Population Sciences, University of Pittsburgh Cancer Institute, Pittsburgh, PA 15232, USA \\ ${ }^{5}$ Department of Epidemiology, Graduate School of Public Health, University of Pittsburgh, Pittsburgh, PA 15232, USA \\ ${ }^{6}$ Department of Medicine, Yong Loo Lin School of Medicine, National University Health System, Singapore 119228, Singapore
}

(Submitted 23 September 2017 - Final revision received 6 December 2017 - Accepted 5 January 2018 - First published online 19 February 2018)

\section{Abstract}

Several previous prospective studies suggest that consumption of green leafy and cruciferous vegetables may lower the risk of type 2 diabetes (T2D). We investigated the association between consumption of different types of vegetables in relation to T2D risk in an Asian Population. We included 45411 participants (age range: 45-74 years) of the Singapore Chinese Health Study (SCHS) free of diabetes, cancer or CVD at baseline (1993-1998). Dietary information was collected using a validated FFQ. Physician-diagnosed incident diabetes was reported at follow-up I (1999-2004) and II (2006-2010) interviews. Cox proportional hazards regression was used to estimate hazard ratio (HR) and 95\% CI of T2D risk. An updated meta-analysis was also conducted to summarise results for green leafy and cruciferous vegetables. During 494741 person-years of follow-up, 5207 incident T2D occurred. After adjustment for potential confounders, neither total vegetables (top $v$. bottom quintile $\left.\mathrm{HR}=1 \cdot 08 ; 95 \% \mathrm{CI} 0 \cdot 98,1 \cdot 18, P_{\text {trend }}=0 \cdot 66\right)$ nor specific vegetables including dark green leafy vegetables $(\mathrm{HR}=1 \cdot 05 ; 95 \% \mathrm{CI} 0 \cdot 96,1 \cdot 15$, $\left.P_{\text {trend }}=0.21\right)$ and cruciferous vegetables ( HR $\left.=0.97 ; 95 \% \mathrm{CI} 0.88,1 \cdot 06, P_{\text {trend }}=0.29\right)$ were substantially associated with risk of T2D. A metaanalysis (eleven studies with 754729 participants and 58297 cases) including the SCHS and all previous prospective studies suggested borderline significant inverse associations between green leafy (summary relative risk (RR) $=0.91 ; 95 \%$ CI 0.84 , 1.00 ) and cruciferous vegetable consumption $(\mathrm{RR}=0.87 ; 95 \% \mathrm{CI} 0.76,1.00)$ and $\mathrm{T} 2 \mathrm{D}$ risk, with moderate-to-high heterogeneity. In conclusion, green leafy or cruciferous vegetable consumption was not substantially associated with risk of T2D in an Asian population. Meta-analysis of available cohort data indicated that evidence for a beneficial effect of green leafy or cruciferous vegetable consumption on T2D risk is not convincing.

\section{Keywords: Vegetables: Diets: Type 2 diabetes: Cohort studies: Meta-analyses}

Vegetables are nutrient-dense plant-based foods that are an important part of healthy dietary patterns ${ }^{(1)}$. Vegetables can be rich sources of dietary fibre, plant protein, phytochemicals, vitamins and minerals, and these bioactive components may independently or jointly contribute to a lower risk of type 2 diabetes (T2D) ${ }^{(2)}$. However, most ${ }^{(3-11)}$ prospective studies have been unable to detect a substantial association between total vegetable consumption and risk of T2D (with a few exceptions ${ }^{(12,13)}$ ), and the lack of association was supported by several meta-analyses ${ }^{(4,14-18)}$. The associations of individual groups of vegetables with T2D risk have been investigated in fewer studies and findings have been less consistent. Among the most frequently assessed vegetable groups, green leafy vegetables and cruciferous vegetables were associated with a lower T2D risk in several prospective studies ${ }^{(3,4,7,9,13)}$ and meta- analyses $^{(4,14-16,19)}$. A specific beneficial effect of green leafy vegetables, if any, may be partially explained by their high Mg content. Cumulative evidence has shown that Mg supplementation may improve glucose homoeostasis and that $\mathrm{Mg}$ intake is inversely associated with risk of $\mathrm{T} 2 \mathrm{D}^{(20,21)}$. However, other studies observed no difference in risk ${ }^{(6,11)}$, or even a higher risk of $\mathrm{T} 2 \mathrm{D}^{(7)}$ associated with green leafy and/or cruciferous vegetable consumption.

To our knowledge, only two prospective studies have investigated vegetable consumption in relation to T2D risk in Asian population ${ }^{(11,13)}$. Total and several specific vegetables were inversely associated with T2D risk in Chinese women ${ }^{(13)}$, but not in Japanese men and women ${ }^{(11)}$. The inconsistency of findings for specific vegetables and the limited cohort data from Asian population highlight the need for additional studies. Thus, we used the

Abbreviations: HR, hazard ratio; RR, relative risk; SCHS, Singapore Chinese Health Study; SWHS, Shanghai Women's Health Study; T2D, type 2 diabetes.

* Corresponding author: Dr R. M. van Dam, fax +65 67791489, email rob.van.dam@nus.edu.sg 
Singapore Chinese Health Study (SCHS), a large population-based prospective study of ethnic Chinese men and women, to examine the associations between total and specific vegetables and risk of T2D. Furthermore, we also conducted an updated meta-analysis that incorporated results from the SCHS and cohort studies ${ }^{(7)}$ that were published after previous meta-analyses ${ }^{(4,14-16,19)}$ to assess the overall evidence for a beneficial effect of green leafy and cruciferous vegetable consumption on risk of T2D.

\section{Methods \\ Study population}

The design of the SCHS has been described elsewhere ${ }^{(22)}$. In brief, a total of 63257 Chinese individuals (35298 women and 27959 men) aged 45-74 years were enrolled between 1993 and 1998. Participants belonged to one of the major dialect groups (Hokkien or Cantonese) of Chinese in Singapore, and were citizens or permanent residents of government-built housing estates where $86 \%$ of the general population resided during the enrolment period. Using a structured questionnaire, in-person interviews were conducted at recruitment to collect subjects' information on habitual diet, demographics, height and weight, tobacco use, physical activity, menstrual and reproductive history (women only) and medical history. The first and second follow-up interviews were conducted by telephone calls during 1999-2004 and 2006-2010, respectively. Informed consents were obtained from all enrolled participants. The study was approved by the Institutional Review Boards of the National University of Singapore and the University of Pittsburgh.

For the present analysis, we excluded individuals who: (1) had self-reported, physician-diagnosed diabetes ( $n$ 5696) or other chronic diseases such as cancer, heart disease or stroke at baseline ( $n$ 4108); (2) reported unrealistically high (>3700 kcal ( $>15480 \mathrm{~kJ}$ ) for men; $>3000 \mathrm{kcal}(>12550 \mathrm{~kJ}$ ) for women) or low ( $<700 \mathrm{kcal}(<2930 \mathrm{~kJ})$ for men; $<600 \mathrm{kcal}(<2510 \mathrm{~kJ})$ for women) daily energy intake (402 men and $467(<2510 \mathrm{~kJ})$ women); and (3) did not respond to both follow-up interviews ( $n$ 7173). After these exclusions, 45411 subjects remained for the present analysis, including 26002 women and 19409 men.

\section{Dietary assessment}

Baseline information on habitual dietary intake over the past year was collected using a 165 -item, semi-quantitative FFQ that was administered by a trained interviewer ${ }^{(22)}$. The FFQ contained twenty-four items that assessed intake of thirty-three types of fresh vegetables. For fresh vegetables and other food items, eight food-frequency categories (ranging from 'never or hardly ever' to 'two or more times a day') and three portion sizes (small, medium, large) with accompanying photographs were available for respondents to denote their habitual intake. The daily intake of each food item was derived by multiplying intake frequency with portion sizes. For non-alcoholic beverages such as coffee, soft drinks and fruit/vegetable juices, nine intake frequency options were available for each item, ranging from 'never or hardly ever' to 'six or more times a day', with the standard serving size assigned as one cup or glass. For total and specific vegetables, the daily quantity of intake was computed as the sum of the above-described fresh vegetables and vegetables mixed in distinct dishes (including rice, noodle and meat dishes, preserved foods, breads and crackers, snacks and dim sum, and fast food and sandwiches), as well as vegetable juices daily consumed, and expressed as $\mathrm{g} / \mathrm{d}$. In addition to total vegetable intake, vegetables were categorised as light green, dark green (all were leafy), yellow and cruciferous vegetables, potatoes and tomatoes (online Supplementary Table S1).

Daily nutrient and total energy intake were computed from the Singapore Food Composition Table that was developed in conjunction with the cohort ${ }^{(22)}$. In our previous validation study of 810 randomly selected cohort participants that compared the FFQ against two 24-h diet recalls, the correlations ranged from 0.24 to 0.79 between the two different methods for dietary energy and nutrients ${ }^{(22)}$. Correlation coefficients were not calculated for food groups such as vegetables. For several nutrients that were substantially contributed by dark green leafy vegetables $(7.2 \%$ of dietary fibre, $55.0 \%$ of $\beta$-carotene, $16.9 \%$ of vitamin $\mathrm{C}$ and $21.5 \%$ of folate) and cruciferous vegetables (8.8\% of dietary fibre, $40.2 \%$ of $\beta$-carotene, $19.4 \%$ of vitamin C and $20.9 \%$ of folate) in our study population, the correlation coefficients ranged from 0.65 to 0.72 for dietary fibre, 0.38 to 0.61 for $\beta$-carotene, 0.63 to 0.67 for vitamin $\mathrm{C}$ and 0.50 to 0.69 for folate, respectively, for the four dialect-sex groups.

\section{Assessment of other covariates}

Data on other covariates such as cigarette smoking, alcohol consumption, physical activity, education level, medical history (physician-diagnosed hypertension, diabetes, heart attack or angina and cancer) and height and weight were also collected using interview-administered questionnaires. Alcohol consumption was assessed by asking subjects their intake frequency of 4 types of commonly consumed alcohol (beer, rice wine, other wine and liquor) in this population, with specific serving sizes being assigned to each alcohol item. Physical activity was assessed by asking subjects the amount of time they spent per week on the following activities over the past year: (1) strenuous sports such as jogging, tennis or swimming; (2) vigorous work such as moving heavy furniture, loading or unloading trucks or shoveling; and (3) moderate activities such as brisk walking, tai chi or chi kung. BMI $\left(\mathrm{kg} / \mathrm{m}^{2}\right)$ was calculated as self-reported weight divided by the square of self-reported height.

\section{Ascertainment of incident diabetes}

Diabetes that occurred during follow-up was assessed through telephone interviews by the following question: 'Have you been told by a doctor that you have diabetes (high blood sugar)?' If yes: 'Please also tell me the age at which you were first diagnosed?' We counted as incident T2D those who reported physician-diagnosed diabetes at any time between the initial enrolment interview and the first (1999-2004) or second (2006-2010) follow-up telephone interviews.

The validation of the self-reported, physician-diagnosed diabetes in this study has been previously described ${ }^{(23,24)}$. Among participants who reported physician-diagnosed diabetes 
at the follow-up I interview, 949 were confirmed to be valid cases by linking with a nationwide hospital-based discharge database. The remaining 1321 participants without diabetesrelated hospitalisation records were contacted to answer a supplementary questionnaire about symptoms, diagnostic tests and hypoglycaemic therapy during a telephone interview. Of these 1321 participants, 702 (53\%) were available for further interview and agreed to be interviewed, of whom 682 (97\%) were confirmed by the supplementary questionnaire ${ }^{(24)}$. Among participants who did not report a diagnosis of diabetes and provided blood samples at the follow-up I interview, 2625 were randomly selected and HbA1c was measured in their blood samples; 2477 (94\%) had an HbA1c $<6.5 \%{ }^{(23)}$.

\section{Statistical analysis}

Person-years of follow-up time for each subject were calculated from the year of the baseline questionnaire until the year of reported initial diagnosis of diabetes or the date of the second follow-up interview, whichever came first. Total and specific vegetable intake were divided by total energy intake and expressed as $\mathrm{g} / 2000 \mathrm{kcal}(8370 \mathrm{~kJ})$ because of the substantial correlation between vegetable and energy intake in this population $(r 0.48)^{(25)}$, and quintiles were created based on these energy-adjusted intake values.

Hazard ratios (HR) and 95\% CI of T2D risk were estimated by Cox proportional hazards model. Three models with different covariates were constructed to account for potential confounders. The first model was adjusted for age at baseline interview (years), year of baseline interview (1993-1995 or 19961998), sex, dialect group (Hokkien or Cantonese) and daily energy intake $(\mathrm{kcal} / \mathrm{d})$. The second model included the variables in model 1 and was additionally adjusted for moderate and vigorous physical activity (no moderate or vigorous/strenuous activity, $<4 \mathrm{~h} /$ week moderate or $<2 \mathrm{~h} /$ week vigorous/strenuous activity or $\geq 4 \mathrm{~h} /$ week moderate or $\geq 2 \mathrm{~h} /$ week vigorous/strenuous activity), the highest education level (no formal education, primary school or secondary school or higher), smoking (never smoker, former smoker, current smoker with 1-12 cigarettes/d or current smoker with $\geq 13$ cigarettes/d), alcohol consumption ( 0 , $<5$ or $\geq 5 \mathrm{~g} / \mathrm{d}$ ), soft drink consumption (glasses/week), coffee consumption (cups/d) and other food groups that may confound the association between vegetable consumption and T2D risk, including red meat, poultry, fish, nuts and seeds, soya products and whole grains $(\mathrm{g} / 2000 \mathrm{kcal}(8370 \mathrm{~kJ}))^{(18,26,27)}$. In the third model, analyses were further adjusted for BMI $\left(\mathrm{kg} / \mathrm{m}^{2}\right)$ and physician-diagnosed hypertension status (yes or no).

$P$ values for linear trends were assessed by fitting median values of intake categories as a continuous variable. We also conducted stratified analyses and tested interactions of total and specific vegetable consumption by sex, BMI $(<25 \cdot 0 v$. $\geq 25 \cdot 0 \mathrm{~kg} / \mathrm{m}^{2}$ ) and smoking status (never $v$. ever smokers). $P$ values for interaction were calculated by including the median values of intake categories as continuous variables and a multiplicative term with sex, BMI or smoking status as a binary variable in the fully adjusted models. To account for potential bias due to undiagnosed diabetes or reverse causality, sensitivity analyses were performed by excluding T2D cases that were diagnosed during the first 4 years of follow-up. A further supplementary analysis was carried out by subtracting preserved vegetables from total vegetables.

\section{Meta-analysis}

We conducted an updated meta-analysis that incorporated results from the SCHS to quantify the prospective relationships between green leafy and cruciferous vegetable consumption and risk of T2D. We conducted a literature search on PubMed from inception to March 15, 2017 using the search terms 'vegetable' and 'diabetes' in combination with 'cohort' or 'prospective'. The literature search was limited to publications that were published in English. Bibliographies in the retrieved full articles and recent meta-analyses ${ }^{(4,14-17,19)}$ were also handsearched for additional studies. We also contacted relevant authors, if necessary, for additional information.

To be included, studies should have a prospective design, investigate the associations between green leafy and/or cruciferous vegetable intake and incidence of T2D and report corresponding HR, relative risks (RR) or OR and 95\% CI that were adjusted for potential confounders. In case of multiple publications from the same population, the one with the largest number of T2D cases was included. Our meta-analysis focused on intakes of green leafy and cruciferous vegetables in relation to $\mathrm{T} 2 \mathrm{D}$ risk. In several prospective studies, only results for cabbage rather than total cruciferous vegetables were reported, and we used these results in a sensitivity analysis for cruciferous vegetable intake. On the basis of these criteria, we excluded six publications ${ }^{(28-33)}$ for which vegetable intake was investigated in the whole dietary patterns, three publications ${ }^{(34-36)}$ in which fruits and vegetables were combined in the analyses, two publications ${ }^{(37,38)}$ that investigated vegetable protein/fibre intake and two publications in which only total vegetables were assessed $^{(5,8)}$. We further excluded two publications ${ }^{(12,39)}$ that were from sub-cohorts of the European Prospective Investigation into Cancer and Nutrition (EPIC) study, because most of the T2D cases in the two sub-cohorts should have been included in another report of the EPIC-InterAct study ${ }^{(4)}$. For the EPIC Elderly study that included participants who were from four European countries $^{(7)}$, we included the Greek sub-cohort that was not included in the EPIC-InterAct study.

We extracted information on various study and population characteristics and we assessed study quality using the nine-star Newcastle-Ottawa Scale ${ }^{(40)}$. We treated OR and HR reported in the primary studies as RR approximations because the incidence of T2D was sufficiently low for the rare disease assumption to apply. We used a random-effects model ${ }^{(41)}$ to calculate summary risk estimates of T2D for the highest compared with the lowest categories of vegetable intake. To explore the potential sources of heterogeneity, we also conducted several subgroup and metaregression analyses according to geographic area, sex, duration of follow-up, measure of association (HR/RR $v$. OR), average vegetable intake and whether adjustments for other dietary factors were made or not. Furthermore, we also conducted a doseresponse analysis by use of the method proposed by Greenland \& Longnecker ${ }^{(42)}$ and Orsini et $a l^{(43)}$. Accordingly, the average (mean or median) intake of vegetables, the number of cases and 
person-years and the risk estimates with their variance for at least three quantitative exposure categories were extracted. Vegetables were expressed as frequency (e.g. servings/d) or weight (e.g. g/d) of intake in the primary studies, and we converted the intake into $\mathrm{g}$ by using $80 \mathrm{~g}$ as a serving size for the studies that reported the intake in frequency ${ }^{(7)}$. Results of the dose-response meta-analysis in the forest plot were presented for a $40-\mathrm{g} / \mathrm{d}$ increment, which approximates the average intake levels across different studies.

Heterogeneity among studies was assessed using the $I^{2}$ statistics $^{(44)}$, with $I^{2}<30 \%, 30-75 \%$ and $>75 \%$ indicating low, moderate and high heterogeneity, respectively. Potential publication bias was investigated with Egger's asymmetry test and funnel plots ${ }^{(45)}$. All analyses were performed using STATA 14.0 (Stata Corp LP). All $P$ values were two-sided, and the level of significance was at $<0 \cdot 05$.

\section{Results}

\section{Cohort analyses}

Baseline characteristics of the study population by quintiles of energy-adjusted vegetable consumption are presented in Table 1 . Higher vegetable consumption was associated with younger age, higher BMI, higher educational achievement, female sex, non-smoking and non-drinking, and lower consumption of coffee and soft drinks. Participants who had higher vegetable consumption were also more likely to be from the Cantonese dialect group, engage in moderate physical activity and have a history of hypertension at baseline.

During 494741 person-years of follow-up, 5207 cases of incident T2D were documented, of which 2195 were male and 3012 were female participants. With the basic adjustment for demographic variables and total energy intake, total vegetable consumption was associated with a non-significant trend towards a higher risk of T2D (model 1: top $v$. bottom $\mathrm{HR}=1 \cdot 13$; 95\% CI: 1.04, 1.24; $P_{\text {trend }}=0.07$ ) (Table 2). Further adjusting for other lifestyle and dietary factors yielded a similar result (model 2: top $v$. bottom $\mathrm{HR}=1.13 ; 95 \%$ CI $\left.1.03,1.24 ; P_{\text {trend }}=0.10\right)$. Additional adjustment for BMI and hypertension further attenuated the association (model 3: HR $=1 \cdot 08 ; 95 \%$ CI 0.98, 1.18; $P_{\text {trend }}=0 \cdot 66$ ) (Table 2).

No substantial associations were observed between specific vegetable consumption and risk of $\mathrm{T} 2 \mathrm{D}$, including dark green leafy vegetables (model 3: top $v$. bottom quintile $\mathrm{HR}=1 \cdot 05$; $95 \%$ CI $\left.0.96,1.15 ; P_{\text {trend }}=0.21\right)$ and cruciferous vegetables (model 3: HR $=0.97 ; 95 \%$ CI 0.88, 1.06; $P_{\text {trend }}=0 \cdot 29$ ) (Table 2). Higher potato consumption was associated with a borderline

Table 1. Baseline characteristics according to quintiles of energy-adjusted ${ }^{*}$ vegetable intake in the Singapore Chinese Health Study (Mean values and standard deviations; percentages)

\begin{tabular}{|c|c|c|c|c|c|c|c|c|c|c|}
\hline & \multicolumn{10}{|c|}{ Vegetable intake quintiles } \\
\hline & \multicolumn{2}{|c|}{1 (low) } & \multicolumn{2}{|c|}{2} & \multicolumn{2}{|c|}{3} & \multicolumn{2}{|c|}{4} & \multicolumn{2}{|c|}{5 (high) } \\
\hline & Mean & SD & Mean & SD & Mean & SD & Mean & SD & Mean & SD \\
\hline Median vegetable intake (g/2000 kcal) & \multicolumn{2}{|c|}{$73 \cdot 3$} & \multicolumn{2}{|c|}{$106 \cdot 3$} & \multicolumn{2}{|c|}{134.6} & \multicolumn{2}{|c|}{$169 \cdot 1$} & \multicolumn{2}{|c|}{$235 \cdot 3$} \\
\hline No. of participants & \multicolumn{2}{|c|}{9082} & \multicolumn{2}{|c|}{9082} & \multicolumn{2}{|c|}{9082} & \multicolumn{2}{|c|}{9082} & \multicolumn{2}{|c|}{9083} \\
\hline Age (years) & $56 \cdot 2$ & 7.9 & $56 \cdot 5$ & $7 \cdot 6$ & $55 \cdot 2$ & 7.6 & $54 \cdot 7$ & 7.4 & $54 \cdot 4$ & 7.3 \\
\hline Male sex (\%) & \multicolumn{2}{|c|}{$59 \cdot 7$} & \multicolumn{2}{|c|}{$49 \cdot 6$} & \multicolumn{2}{|c|}{$42 \cdot 1$} & \multicolumn{2}{|c|}{35.4} & \multicolumn{2}{|c|}{$26 \cdot 9$} \\
\hline \multicolumn{11}{|l|}{ Dialect group (\%) } \\
\hline Cantonese & \multirow{2}{*}{\multicolumn{2}{|c|}{$\begin{array}{l}44.8 \\
55.2\end{array}$}} & \multicolumn{2}{|c|}{$47 \cdot 2$} & \multicolumn{2}{|c|}{$48 \cdot 7$} & \multicolumn{2}{|c|}{$48 \cdot 3$} & \multicolumn{2}{|c|}{49.5} \\
\hline Hokkien & & & & & & & & & & \\
\hline \multicolumn{11}{|l|}{ Highest education (\%) } \\
\hline No formal education & & & & & & & & & & \\
\hline Primary school & & & & & & & & & & \\
\hline Secondary school or higher & & & & & & & & & & \\
\hline BMI $\left(\mathrm{kg} / \mathrm{m}^{2}\right)$ & $22 \cdot 7$ & $3 \cdot 2$ & 22.9 & $3 \cdot 1$ & $23 \cdot 0$ & $3 \cdot 2$ & $23 \cdot 2$ & $3 \cdot 3$ & $23 \cdot 3$ & $3 \cdot 3$ \\
\hline Current smoker (\%) & & & & & & & & & & \\
\hline Any alcohol drinker (\%) & & & & & & & & & & \\
\hline Coffee consumption $\geq 1$ cup/d (\%) & & & & & & & & & & \\
\hline Soft drink consumption $\geq 1$ glass/week (\%) & & & & & & & & & & \\
\hline Physical activity (\%) & & & & & & & & & & \\
\hline No moderate or vigorous activity & & & & & & & & & & \\
\hline$<4 \mathrm{~h} /$ week moderate or $<2 \mathrm{~h} /$ week vigorous & & & & & & & & & & \\
\hline$\geq 4 \mathrm{~h} /$ week moderate or $\geq 2 \mathrm{~h} /$ week vigorous & & & & & & & & & & \\
\hline Hypertension (\%) & & & & & & & & & & \\
\hline Dietary intakes & & & & & & & & & & \\
\hline Total energy $(\mathrm{kcal} / \mathrm{d})$ & 1662 & 546 & 1616 & 542 & 1567 & 516 & 1523 & 496 & 1467 & 484 \\
\hline Whole grains (g/2000 kcal) & $7 \cdot 1$ & $15 \cdot 8$ & 7.5 & $15 \cdot 4$ & 7.9 & $15 \cdot 5$ & $8 \cdot 2$ & $15 \cdot 4$ & $9 \cdot 2$ & $16 \cdot 1$ \\
\hline Soya products (g/2000 kcal) & $106 \cdot 7$ & $86 \cdot 0$ & $128 \cdot 2$ & $86 \cdot 8$ & $140 \cdot 9$ & $91 \cdot 1$ & 154.9 & 96.5 & $180 \cdot 8$ & $115 \cdot 3$ \\
\hline Nuts and seeds ( $\mathrm{g} / 2000 \mathrm{kcal})$ & 2.9 & $4 \cdot 3$ & $3 \cdot 1$ & $4 \cdot 2$ & $3 \cdot 2$ & $4 \cdot 2$ & 3.2 & 4.4 & 3.3 & 4.5 \\
\hline Red meat $(\mathrm{g} / 2000 \mathrm{kcal})$ & $37 \cdot 0$ & $22 \cdot 3$ & $39 \cdot 9$ & $22 \cdot 1$ & $39 \cdot 8$ & $21 \cdot 7$ & $38 \cdot 6$ & $21 \cdot 8$ & 34.0 & 21.8 \\
\hline Fish $(\mathrm{g} / 2000 \mathrm{kcal})$ & $59 \cdot 7$ & $30 \cdot 7$ & 68.7 & 31.6 & $73 \cdot 6$ & $32 \cdot 1$ & 77.5 & 34.5 & $80 \cdot 3$ & 39.9 \\
\hline Poultry (g/2000 kcal) & 23.9 & $18 \cdot 1$ & $26 \cdot 7$ & $19 \cdot 1$ & $26 \cdot 9$ & $19 \cdot 0$ & $26 \cdot 5$ & 19.5 & $24 \cdot 7$ & $20 \cdot 6$ \\
\hline
\end{tabular}

* Vegetable (and also other foods listed in the table) intake was divided by total energy intake and expressed as $\mathrm{g} / 2000 \mathrm{kcal}(1 \mathrm{kcal}=4 \cdot 184 \mathrm{~kJ})$. 
Table 2. Type 2 diabetes by quintile of energy-adjusted ${ }^{*}$ total and specific vegetable intake in the Singapore Chinese Health Study (Hazard ratios (HR) and $95 \%$ confidence intervals)

\begin{tabular}{|c|c|c|c|c|c|c|c|c|c|c|}
\hline & \multicolumn{10}{|c|}{ Vegetable intake quintiles } \\
\hline & \multirow[b]{2}{*}{1 (low) } & \multicolumn{2}{|r|}{2} & \multicolumn{2}{|r|}{3} & \multicolumn{2}{|r|}{4} & \multicolumn{2}{|c|}{5 (high) } & \multirow[b]{2}{*}{$P_{\text {trend }} \dagger$} \\
\hline & & $\mathrm{HR}$ & $95 \% \mathrm{Cl}$ & $\mathrm{HR}$ & $95 \% \mathrm{Cl}$ & $\mathrm{HR}$ & $95 \% \mathrm{Cl}$ & $\mathrm{HR}$ & $95 \% \mathrm{Cl}$ & \\
\hline \multicolumn{11}{|l|}{ Total vegetables } \\
\hline No. of cases/person-years & $981 / 95037$ & \multicolumn{2}{|c|}{$1140 / 95490$} & \multicolumn{2}{|c|}{$981 / 95725$} & \multicolumn{2}{|c|}{$1031 / 95052$} & \multicolumn{2}{|c|}{ 1074/94 154} & \\
\hline Median intake ( $\mathrm{g} / 2000 \mathrm{kcal})$ & $73 \cdot 3$ & \multicolumn{2}{|c|}{$106 \cdot 3$} & \multicolumn{2}{|c|}{134.6} & \multicolumn{2}{|c|}{$169 \cdot 1$} & \multicolumn{2}{|c|}{$235 \cdot 3$} & \\
\hline Model $1 \ddagger$ & 1.00 & $1 \cdot 17$ & $1.07,1.27$ & 1.01 & $0.92,1 \cdot 10$ & 1.07 & $0.98,1.17$ & $1 \cdot 13$ & $1.04,1.24$ & 0.07 \\
\hline Model $2 \S$ & 1.00 & $1 \cdot 16$ & $1.06,1.26$ & 0.99 & $0.90,1.08$ & 1.05 & $0.96,1.15$ & 1.13 & $1.03,1.24$ & $0 \cdot 10$ \\
\hline Model 3॥ & 1.00 & $1 \cdot 16$ & $1.06,1.26$ & 0.98 & $0.89,1.07$ & 1.02 & $0.93,1.11$ & 1.08 & $0.98,1.18$ & 0.66 \\
\hline \multicolumn{11}{|l|}{ Light green vegetables } \\
\hline No. of cases/person-years & $996 / 94155$ & \multicolumn{2}{|c|}{ 1025/95732 } & & 3/96006 & & 1/95026 & & //94538 & \\
\hline Median intake (g/2000 kcal) & $18 \cdot 1$ & & $28 \cdot 2$ & & $37 \cdot 0$ & & $48 \cdot 0$ & & $70 \cdot 2$ & \\
\hline Model $1 \ddagger$ & 1.00 & 1.02 & $0.93,1.11$ & 1.06 & $0.97,1.16$ & 1.09 & $1.00,1.19$ & 1.05 & $0.96,1.15$ & $0 \cdot 16$ \\
\hline Model $2 \S$ & 1.00 & 1.00 & $0.92,1.09$ & 1.04 & $0.95,1.13$ & 1.06 & $0.97,1.16$ & 1.03 & $0.94,1.13$ & 0.32 \\
\hline Model 3\| & 1.00 & 0.99 & $0.90,1.08$ & 0.98 & $0.90,1.08$ & 1.02 & $0.93,1.11$ & 0.95 & $0.87,1.04$ & 0.36 \\
\hline Dark green leafy vegetables & & & & & & & & & & \\
\hline No. of cases/person-years & 1036/94990 & & 2/96 110 & & /95 136 & & $5 / 94644$ & & 1/94 578 & \\
\hline Median intake ( $\mathrm{g} / 2000 \mathrm{kcal})$ & 17.8 & & 30.0 & & $41 \cdot 1$ & & 55.5 & & 33.9 & \\
\hline Model $1 \ddagger$ & 1.00 & 0.97 & $0.89,1.05$ & 1.05 & $0.96,1.14$ & 0.99 & $0.91,1.09$ & 1.09 & $1.00,1.19$ & 0.13 \\
\hline Model $2 \S$ & 1.00 & 0.96 & $0.88,1.05$ & 1.04 & $0.95,1.13$ & 0.98 & $0.89,1.07$ & 1.08 & $0.98,1.18$ & 0.06 \\
\hline Model 3\| & 1.00 & 0.96 & $0.88,1.04$ & 1.03 & $0.94,1.12$ & 0.96 & $0.88,1.05$ & 1.05 & $0.96,1.15$ & 0.21 \\
\hline Cruciferous vegetables & & & & & & & & & & \\
\hline No. of cases/person-years & $1035 / 94437$ & & 9/95493 & & 7/95676 & & /95382 & & /94 470 & \\
\hline Median intake (g/2000 kcal) & 24.1 & & $38 \cdot 6$ & & $51 \cdot 6$ & & $58 \cdot 0$ & & $01 \cdot 1$ & \\
\hline Model $1 \ddagger$ & 1.00 & 1.00 & $0.92,1.09$ & 1.06 & $0.97,1.15$ & 0.96 & $0.88,1.05$ & 1.03 & $0.95,1.13$ & 0.73 \\
\hline Model $2 \S$ & 1.00 & 0.99 & $0.91,1.08$ & 1.04 & $0.95,1.13$ & 0.94 & $0.86,1.03$ & 1.02 & $0.93,1.12$ & 0.97 \\
\hline Model 3\| & 1.00 & 0.97 & $0.89,1.06$ & 1.02 & $0.94,1 \cdot 12$ & 0.90 & $0.82,0.98$ & 0.97 & $0.88,1.06$ & 0.29 \\
\hline Yellow vegetables & & & & & & & & & & \\
\hline No. of cases/person-years & 1062/93198 & & 4/96861 & & b/96 414 & & |/95271 & & 93713 & \\
\hline Median intake ( $\mathrm{g} / 2000 \mathrm{kcal})$ & $1 \cdot 2$ & & 4.5 & & $7 \cdot 6$ & & $12 \cdot 1$ & & 23.7 & \\
\hline Model $1 \ddagger$ & 1.00 & 0.93 & $0.85,1.01$ & 0.93 & $0.86,1.02$ & 1.02 & $0.94,1.12$ & 0.94 & $0.86,1.03$ & 0.66 \\
\hline Model $2 \S$ & 1.00 & 0.94 & $0.86,1.03$ & 0.95 & $0.87,1.04$ & 1.04 & $0.96,1.14$ & 0.97 & $0.89,1.07$ & 0.76 \\
\hline Model 3॥ & 1.00 & 0.94 & $0.87,1.03$ & 0.95 & $0.87,1.03$ & 1.05 & $0.96,1.14$ & 0.97 & $0.88,1.06$ & 0.93 \\
\hline Potatoes & & & & & & & & & & \\
\hline No. of cases/person-years & $1058 / 93635$ & & 9/95706 & & 3/95855 & & /95856 & & 194 406 & \\
\hline Median intake $(\mathrm{g} / 2000 \mathrm{kcal})$ & 0.03 & & $2 \cdot 3$ & & $4 \cdot 6$ & & $7 \cdot 5$ & & 14.7 & \\
\hline Model $1 \ddagger$ & 1.00 & 1.00 & $0.91,1.08$ & 0.95 & $0.87,1.03$ & 0.99 & $0.91,1.08$ & 0.93 & $0.85,1.01$ & 0.09 \\
\hline Model $2 \S$ & 1.00 & 0.99 & $0.91,1.08$ & 0.94 & $0.86,1.03$ & 0.99 & $0.90,1.07$ & 0.91 & $0.84,1.00$ & 0.05 \\
\hline Model 3\| & 1.00 & 1.02 & $0.94,1.11$ & 0.97 & $0.89,1.06$ & 1.02 & $0.94,1.11$ & 0.95 & $0.87,1.04$ & 0.24 \\
\hline Tomatoes & & & & & & & & & & \\
\hline No. of cases/person-years & $964 / 93408$ & & 1/96365 & & 5/96848 & & $1 / 95600$ & & 3/93238 & \\
\hline Median intake (g/2000 kcal) & 0.74 & & $3 \cdot 7$ & & $6 \cdot 7$ & & 10.5 & & $22 \cdot 1$ & \\
\hline Model $1 \ddagger$ & 1.00 & 1.06 & $0.96,1.15$ & 1.09 & $1.00,1.19$ & $1 \cdot 12$ & $1.03,1.22$ & 1.07 & $0.98,1.17$ & $0 \cdot 16$ \\
\hline Model $2 \S$ & 1.00 & 1.04 & $0.95,1.14$ & 1.08 & $0.99,1.18$ & $1 \cdot 11$ & $1.02,1.21$ & 1.08 & $0.99,1.18$ & 0.10 \\
\hline Model 3॥ & 1.00 & 1.02 & $0.93,1.11$ & 1.08 & $0.99,1.18$ & 1.09 & $1.00,1.19$ & 1.06 & $0.97,1.16$ & 0.19 \\
\hline Preserved vegetables & & & & & & & & & & \\
\hline No. of cases/person-years & $1045 / 92383$ & & 5/95048 & & 3/96 101 & & 2/96 163 & & /95762 & \\
\hline Median intake $(\mathrm{g} / 2000 \mathrm{kcal})$ & 1.9 & & 4.9 & & $7 \cdot 3$ & & $10 \cdot 8$ & & 20.9 & \\
\hline Model $1 \ddagger$ & 1.00 & 0.93 & $0.86,1.02$ & 0.95 & $0.87,1.03$ & 0.99 & $0.91,1.08$ & 0.97 & $0.89,1.06$ & 0.89 \\
\hline Model $2 \S$ & 1.00 & 0.93 & $0.86,1.02$ & 0.94 & $0.86,1.02$ & 0.97 & $0.89,1.06$ & 0.97 & $0.89,1.06$ & 0.95 \\
\hline Model 3॥ & 1.00 & 0.91 & $0.84,1.00$ & 0.95 & $0.87,1.04$ & 0.99 & $0.90,1.08$ & 0.97 & $0.89,1.06$ & 0.78 \\
\hline
\end{tabular}

* Vegetable intake was divided by total energy intake and expressed as $\mathrm{g} / 2000 \mathrm{kcal}(1 \mathrm{kcal}=4.184 \mathrm{~kJ})$.

† Tests for trends were assessed by fitting median values of intake for quintiles as continuous variables in statistical models.

¥ Model 1 includes age at baseline interview (years), sex, dialect group (Hokkien or Cantonese), year of baseline interview (1993-1995 or 1996-1998) and energy intake (kcal/d).

$\S$ Model 2: model 1 plus physical activity (no moderate or vigorous, $<4 \mathrm{~h} /$ week moderate or $<2 \mathrm{~h} /$ week vigorous, $\geq 4 \mathrm{~h} /$ week moderate or $\geq 2 \mathrm{~h} /$ week vigorous), education (no formal, primary school or secondary school or higher), smoking (never, former, current with $1-12$ cigarettes/d or current with $\geq 13$ cigarettes/d), alcohol consumption ( $0,<5$ or $\geq 5 \mathrm{~g} / \mathrm{d}$ ), soft drink consumption (glasses/week), coffee consumption (cups/d) and energy-adjusted intakes ( $\mathrm{g} / 2000 \mathrm{kcal}$ ) of red meat, poultry, fish, nuts and seeds, soya products and whole grains. II Model 3: model 2 plus BMl $\left(\mathrm{kg} / \mathrm{m}^{2}\right)$ and history of hypertension (yes, no).

significant lower risk of T2D after adjusting for the potential confounders in model $2(\mathrm{HR}=0.91 ; 95 \% \mathrm{CI} 0 \cdot 84,1 \cdot 00$; $\left.P_{\text {trend }}=0.05\right)$, but the association lost significance after further adjusting for BMI and hypertension $\left(P_{\text {trend }}=0 \cdot 24\right)$.

In stratified analyses, the lack of associations between total and specific vegetables and risk of T2D were largely consistent in the analyses by sex, BMI and smoking status (online Supplementary Table S2). In ever-smokers, light green vegetable intake was associated with a significant $\left(P_{\text {trend }}=0.04\right)$ and cruciferous vegetable intake was associated with a borderline significant $\left(P_{\text {trend }}=0.05\right)$ lower risk of T2D, but no significant interaction with smoking status was observed $\left(P_{\text {interaction }}=0 \cdot 11\right.$ 
and $0 \cdot 22$, respectively). There was a suggestion that the association with preserved vegetable differed by sex $\left(P_{\text {interaction }}=0.01\right)$, with a marginally significant, direct association in men (model 3: top $v$. bottom quintile $\mathrm{HR}=1 \cdot 12 ; 95 \% \mathrm{CI}$ $\left.0.98,1.29 ; P_{\text {trend }}=0.05\right)$, but not in women $(\mathrm{HR}=0.89 ; 95 \% \mathrm{CI}$ $0.79,1.00 ; P_{\text {trend }}=0.21$ ) (online Supplementary Table S2).

When light green and dark green leafy vegetables were combined as total green vegetables, the lack of association remained (model 3: top $v$. bottom quintile $\mathrm{HR}=1 \cdot 03$; $95 \% \mathrm{CI}$ $0.94,1 \cdot 13 ; P_{\text {trend }}=0 \cdot 22$ ). Excluding T2D cases that occurred during the first 4 years of follow-up did not substantially change the associations between consumption of total vegetables or any of the specific vegetable groups and risk of T2D (data not shown). Subtracting preserved vegetables from total vegetables did not appreciably alter the results (data not shown).

\section{Meta-analysis}

Results of the literature search and selection of studies for the meta-analysis are provided in detail in Fig. 1. Eleven prospective studies, including the SCHS and others from nine publications $^{(3,4,6,7,9-11,13,46)}$ (two cohorts were reported in one publication $^{(7)}$ and one cohort ${ }^{(46)}$ on cabbage intake was included in our sensitivity analysis), were included in the metaanalysis, involving 754729 participants and 58297 incident T2D cases. The studies were largely conducted in the USA or Europe, in addition to three studies that were from China ${ }^{(13)}$, Japan $^{(11)}$ or Singapore (the SCHS), respectively. The duration of follow-up ranged from 4.6 to 23 years. Consumption of vegetables was mostly assessed using FFQ by self-reports or interviews, with the only exception of one cohort ${ }^{(10)}$ where diet records were used. Characteristics of the studies are presented in Table 3. Types of individual vegetables that contributed to green leafy or cruciferous vegetables differed substantially across studies (online Supplementary Table S3). The online Supplemental Table S4 presents details of quality assessment for the included studies according to the nine-star NewcastleOttawa Scale.

The summary RR for the highest compared with lowest intake of green leafy vegetables was 0.91 (95\% CI 0.84, 1.00) based on nine studies (50 499 cases and 697337 participants), and there was moderate-to-high heterogeneity among studies $\left(I^{2}=72 \cdot 3 \%\right.$ ) (Fig. 2). The corresponding RR for cruciferous vegetable intake was 0.87 (95\% CI 0.76, 1.00, $I^{2}=63 \cdot 8 \%$ ) based on five studies (9757 cases and 198389 participants) (Fig. 2). There was a suggestion of funnel plot asymmetry for studies of green leafy vegetables (online Supplementary Fig. S1), but this was based on a small number of studies and the Egger test did not provide evidence for publication bias $(P=0.57$ for green leafy vegetables and $P=0.56$ for cruciferous vegetables).

In the stratified and meta-regression analyses (online Supplementary Table S5), none of the predefined factors was found to be a significant contributor to the heterogeneity ( $P_{\text {difference }} \geq 0 \cdot 12$ ). The summary RR for cabbage intake and T2D risk based on four studies (three publications ${ }^{(4,7,46)}$ ) was 0.98 (95\% CI $0.92,1.04, I^{2}=35.9 \%$ ). When combining studies on cruciferous vegetables and cabbage in a sensitivity analysis, the summary RR of T2D was 0.93 (95\% CI $0.87,1.00, I^{2}=57.3 \%$ ). Results of meta-analysis were similar when the estimate for dark green leafy vegetables in the SCHS was replaced with the one for total green vegetables (data not shown).

One study ${ }^{(10)}$ on cruciferous vegetables was not eligible for the dose-response analysis because the intake levels were not available across quartile of cruciferous vegetables.

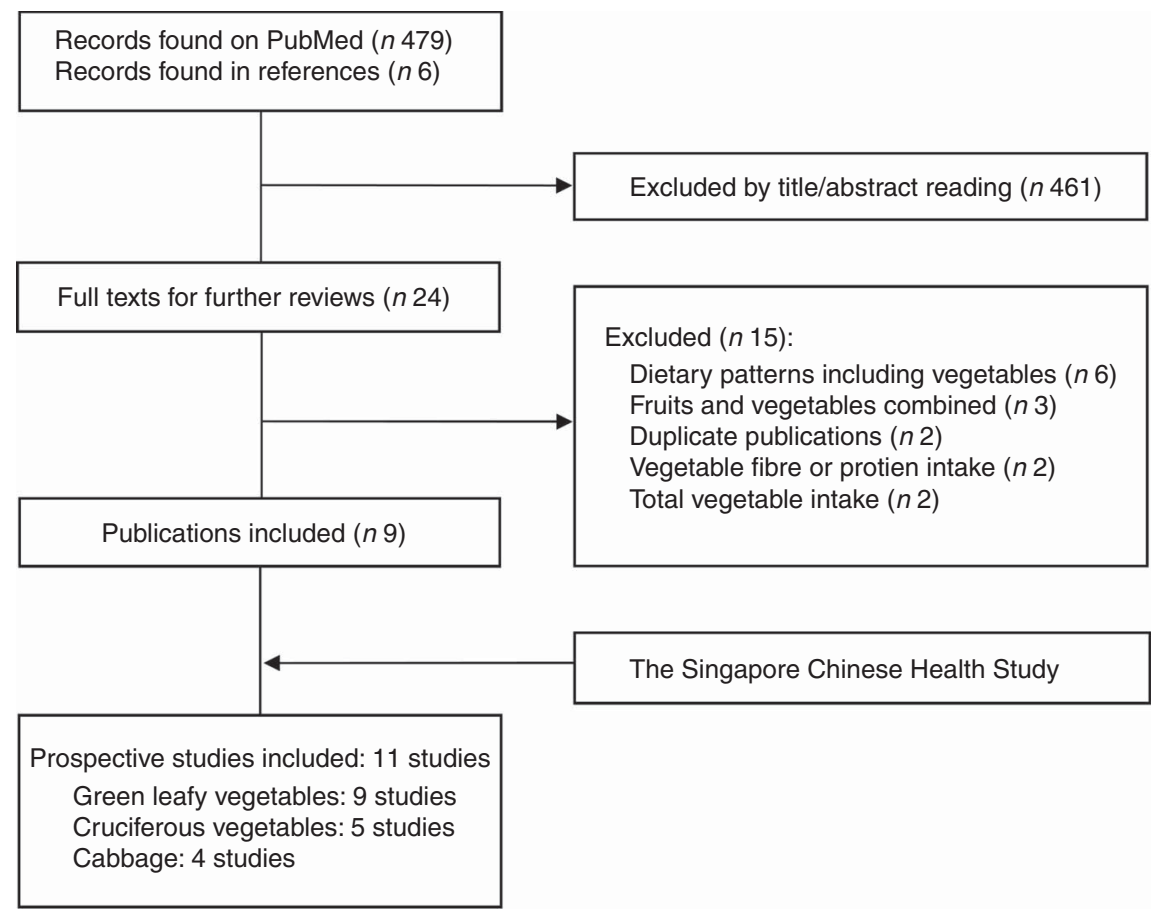

Fig. 1. Literature search and selection of studies for the meta-analysis. 


\section{Nesitish Journal of Nutrition}

Table 3. Characteristics of prospective studies on green leafy vegetable and cruciferous vegetable intake and risk of type 2 diabetes

\begin{tabular}{|c|c|c|c|c|c|c|c|c|c|}
\hline $\begin{array}{l}\text { First author, year } \\
\text { (ref.), country }\end{array}$ & $\begin{array}{l}\text { Study name and } \\
\text { duration }\end{array}$ & $\begin{array}{l}\text { No. of case/ } \\
\text { participants }\end{array}$ & Age and sex & $\begin{array}{l}\text { Assessment of } \\
\text { vegetables }\end{array}$ & $\begin{array}{l}\text { Diagnosis of } \\
\text { diabetes }\end{array}$ & $\begin{array}{l}\text { Type of vegetables } \\
\text { (average intake) }\end{array}$ & Comparison & $\begin{array}{l}\text { Measure of } \\
\text { association }\end{array}$ & Statistical adjustment \\
\hline Liu, $2004^{(6)}$, USA & WHS, 8.8 year & $1614 / 38018$ & $\geq 45$ year, $\mathrm{W}$ & $\begin{array}{l}\text { Self-administered } \\
\text { FFQ (validated) }\end{array}$ & Self-report & $\begin{array}{l}\text { Green leafy veg } \\
\quad(0.56 \text { serv/d), } \\
\text { cruciferous veg } \\
(0.35 \text { serv/d) }\end{array}$ & Quintiles & $\mathrm{RR}$ & $\begin{array}{l}\text { Age, BMI, smoking, alcohol } \\
\text { consumption, exercise, histories } \\
\text { of hypertension and high } \\
\text { cholesterol, family history of } \\
\text { diabetes, and energy intake }\end{array}$ \\
\hline $\begin{array}{l}\text { Montonen, } 2005^{(9)} \text {, } \\
\text { Finland }\end{array}$ & FMCHES, 23 year & $383 / 4304$ & $\begin{array}{l}\text { 40-69 year, } \\
\text { M\&W }\end{array}$ & $\begin{array}{l}\text { Interview-based } \\
\text { FFQ (validated) }\end{array}$ & $\begin{array}{l}\text { Medication use } \\
\quad \text { (drug registers) }\end{array}$ & Green veg $(24 \mathrm{~g} / \mathrm{d})$ & Quartiles & $\mathrm{RR}$ & $\begin{array}{l}\text { Age, sex, BMI, smoking, family } \\
\text { history of diabetes, geographic } \\
\text { area and energy intake }\end{array}$ \\
\hline $\begin{array}{l}\text { Villegas, } \\
2008^{(13)} \text {, China }\end{array}$ & SWHS, 4.6 year & 1608/64 191 & 40-70 year, $W$ & $\begin{array}{l}\text { Interview-based } \\
\text { FFQ (validated) }\end{array}$ & Self-report & $\begin{array}{l}\text { Cruciferous veg } \\
(17.0 \mathrm{~g} / \mathrm{d}), \mathrm{green} / \\
\text { leafy veg }(70.7 \mathrm{~g} / \mathrm{d})\end{array}$ & Quintiles & $\mathrm{HR}$ & $\begin{array}{l}\text { Age, BMI, WHR, smoking, alcohol } \\
\text { consumption, physical activity, } \\
\text { income, education, occupation, } \\
\text { hypertension and intakes of } \\
\text { energy and meat }\end{array}$ \\
\hline $\begin{array}{l}\text { Bazzano, } \\
2008^{(3)}, \text { USA }\end{array}$ & NHS, 18 year & $4529 / 71346$ & $38-63, \mathrm{~W}$ & $\begin{array}{l}\text { Self-administered } \\
\text { FFQ (validated } \\
\text { and updated) }\end{array}$ & Self-report & $\begin{array}{l}\text { Green leafy veg } \\
(0.72 \text { serv/d })\end{array}$ & Quintiles & $\mathrm{HR}$ & $\begin{array}{l}\text { Age, BMI, physical activity, family } \\
\text { history of diabetes, } \\
\text { postmenopausal hormone use, } \\
\text { alcohol consumption, smoking, } \\
\text { and intakes of whole grains, } \\
\text { nuts, processed meats, coffee, } \\
\text { potatoes, sugar-sweetened soft } \\
\text { drinks and energy }\end{array}$ \\
\hline $\begin{array}{l}\text { Cooper, } 2012^{(4)} \\
\text { Eight European } \\
\text { countries }\end{array}$ & $\begin{array}{c}\text { EPIC-InterAct, } \\
11.0 \text { year }\end{array}$ & $12403 / 16154$ & $\mathrm{NR}, \mathrm{M} \& \mathrm{~W}$ & $\begin{array}{l}\text { Self-administered } \\
\text { FFQ (validated) }\end{array}$ & $\begin{array}{l}\text { Self-report, care } \\
\text { registers, } \\
\text { medication } \\
\text { use (drug } \\
\text { registers), etc. }\end{array}$ & $\begin{array}{l}\text { Green leafy veg } \\
\quad(14.1 \mathrm{~g} / \mathrm{d}), \\
\text { cabbages }(8.5 \mathrm{~g} / \mathrm{d})\end{array}$ & Quartiles & $\mathrm{HR}$ & $\begin{array}{l}\text { Age, country, centre, sex, } \\
\text { education, BMI, physical } \\
\text { activity, smoking, alcohol } \\
\text { consumption and energy intake. }\end{array}$ \\
\hline $\begin{array}{l}\text { Kurotani, } \\
2013^{(11)} \text {, Japan }\end{array}$ & JPHC, 5 year & $\begin{array}{l}530 / 21269 \\
(\mathrm{M}) \text { and } 366 / \\
27168(\mathrm{~W})\end{array}$ & $\begin{array}{l}\text { 45-75 year, } \\
\text { M\&W }\end{array}$ & $\begin{array}{l}\text { Self-administered } \\
\text { FFQ (validated) }\end{array}$ & Self-report & $\begin{array}{l}\text { Men: green leafy veg } \\
(16.3 \mathrm{~g} / \mathrm{d}), \\
\text { cruciferous veg } \\
(48.5 \mathrm{~g} / \mathrm{d}) ; \text { women: } \\
\text { green leafy veg } \\
(22.5 \mathrm{~g} / \mathrm{d}), \\
\text { cruciferous veg } \\
(59.4 \mathrm{~g} / \mathrm{d})\end{array}$ & Quartiles & OR & $\begin{array}{l}\text { Age, area, BMI, smoking status, } \\
\text { alcohol consumption, leisure- } \\
\text { time activity, history of } \\
\text { hypertension, family history of } \\
\text { diabetes, coffee consumption } \\
\text { and intakes of } \mathrm{Mg}, \mathrm{Ca} \text { and } \\
\text { energy }\end{array}$ \\
\hline $\begin{array}{l}\text { Mursu, } \\
2014^{(10)} \text {, Finland }\end{array}$ & $\begin{array}{l}\text { KIHDRFS, } 19 \cdot 3 \\
\text { year }\end{array}$ & $432 / 2332$ & $42-60$ year, $\mathrm{M}$ & 4-d food record & FPG and OGTT & $\begin{array}{l}\text { Cruciferous veg } \\
(11 \mathrm{~g} / \mathrm{d})\end{array}$ & Quartiles & $\mathrm{HR}$ & $\begin{array}{l}\text { Age, examination years, BMI, } \\
\text { WHR, smoking, alcohol } \\
\text { consumption, education, } \\
\text { leisure-time physical activity, } \\
\text { family history of diabetes and } \\
\text { energy intake }\end{array}$ \\
\hline $\begin{array}{l}\text { Lacoppidan, } \\
2015^{(46)}, \\
\text { Denmark }\end{array}$ & $\mathrm{DCH}, 15.3$ year & $\begin{array}{c}4097 / 26107(\mathrm{M}) \& \\
3269 / 28953(\mathrm{~W})\end{array}$ & $\begin{array}{l}\text { 50-64 year, } \\
\text { M\&W }\end{array}$ & $\begin{array}{l}\text { Self-administered } \\
\text { FFQ (validated) }\end{array}$ & Diabetes registry & $\begin{array}{l}\text { Men: cabbage } \\
\text { (14 g/d); women: } \\
\text { cabbage }(16 \mathrm{~g} / \mathrm{d})\end{array}$ & $\begin{array}{l}\geq \text { Median or } \\
\text { not }\end{array}$ & $\mathrm{HR}$ & $\begin{array}{l}\text { Age, BMl, WC, education, } \\
\text { participation in sports, smoking, } \\
\text { alcohol consumption, and } \\
\text { intakes of red and processed } \\
\text { meat and energy }\end{array}$ \\
\hline $\begin{array}{l}\text { Mamluk }_{2016^{(\zeta)}} \text {, USA } \\
\end{array}$ & $\begin{array}{l}\text { NIH-AARP, } 10 \cdot 6 \\
\text { year }\end{array}$ & $22782 / 401909$ & $\begin{array}{l}62 \text { year (mean), } \\
\text { M\&W }\end{array}$ & $\begin{array}{l}\text { Self-administered } \\
\text { FFQ (validated) }\end{array}$ & Self-report & $\begin{array}{l}\text { Leafy green veg } \\
(2 \cdot 3 \text { serv/week), } \\
\text { cabbage } \\
(0.3 \text { serv/week })\end{array}$ & Quartiles & OR & $\begin{array}{l}\text { Age, sex, BMI, physical activity, } \\
\text { smoking, alcohol consumption, } \\
\text { education and energy intake }\end{array}$ \\
\hline $\begin{array}{l}\text { Mamluk }_{2016^{(7)}} \text {, Greece }\end{array}$ & $\begin{array}{l}\text { EPIC Elderly } \\
\text { Greece, } 10 \cdot 0 \\
\text { year }\end{array}$ & $1077 / 7567$ & $\begin{array}{l}67 \text { year (mean), } \\
\text { M\&W }\end{array}$ & $\begin{array}{l}\text { Self-administered } \\
\text { FFQ (validated) }\end{array}$ & Self-report & $\begin{array}{l}\text { Leafy green veg } \\
\text { ( } 4.1 \text { serv/week), } \\
\text { cabbage } \\
\text { ( } 1.9 \text { serv/week) }\end{array}$ & Quartiles & OR & $\begin{array}{l}\text { Age, sex, BMI, physical activity, } \\
\text { smoking, alcohol consumption, } \\
\text { education and energy intake }\end{array}$ \\
\hline
\end{tabular}

WHS, Women's Health Study; W, women; serv, servings; veg, vegetables; RR, relative risk; M, men; FMCHES, Finnish Mobile Clinic Health Examination Survey; SWHS, Shanghai Women's Health Study; HR, hazard ratio; WHR, waist:hip ratio; NHS, Nurses' Health Study; EPIC, European Prospective Investigation into Cancer and Nutrition; NR, not reported; JPHC, Japan Public Health Center-based Prospective Study; KIHDRFS, Kuopio Ischaemic Heart Disease Risk Factor Study; FPG, fasting plasma glucose; OGTT, oral glucose tolerance test; WC, waist circumference; DCH, Diet, Cancer and Health; AARP, American Association of Retired Persons. 


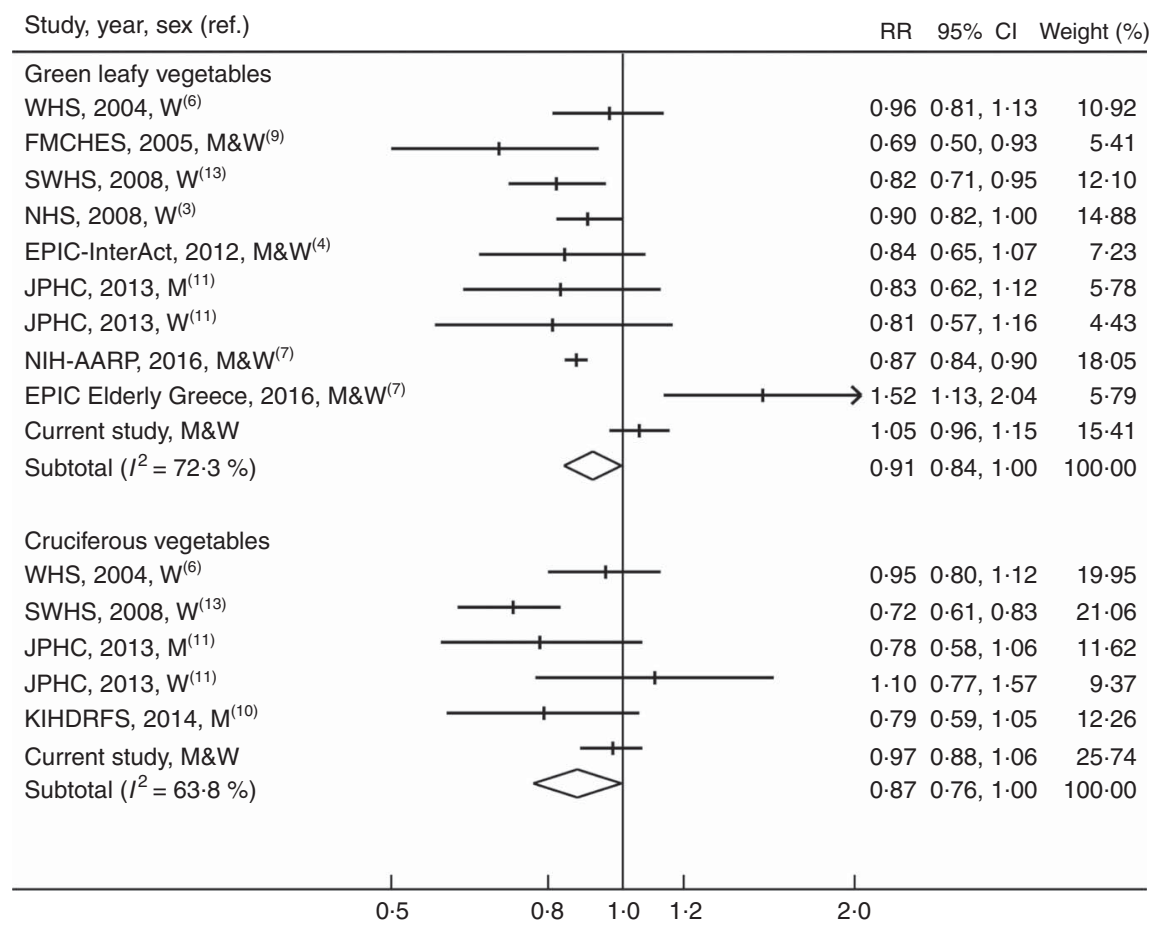

Fig. 2. Meta-analysis of green leafy vegetable and cruciferous vegetable intake (high $v$. low) and risk of type 2 diabetes. WHS, Women's Health Study; W, women; FMCHES, Finnish Mobile Clinic Health Examination Survey; M, men; SWHS, Shanghai Women's Health Study; NHS, Nurses' Health Study; EPIC, European Prospective Investigation into Cancer and Nutrition; JPHC, Japan Public Health Center-based Prospective Study; AARP, American Association of Retired Persons; KIHDRFS, Kuopio Ischaemic Heart Disease Risk Factor Study.

A dose-response meta-analysis of the remaining studies yielded a summary RR of 0.97 ( $95 \%$ CI $0.94,1 \cdot 00, I^{2}=70 \cdot 8 \%$ ) for a $40-\mathrm{g} / \mathrm{d}$ increment in green leafy vegetable intake and 0.93 (95\% CI $0.85,1.03, I^{2}=78.5 \%$ ) for the same increment in cruciferous vegetable intake (online Supplementary Fig. S2).

\section{Discussion}

In a large, population-based, prospective study of ethnic Chinese men and women, we found no substantial associations between total vegetable intake or intake of specific vegetable groups, including green leafy and cruciferous vegetables, and risk of T2D. In a meta-analysis including results from published studies and the SCHS with up to 58000 incident cases, high green leafy and cruciferous vegetable intake was associated with a 9 and $13 \%$ lower risk of T2D, respectively, but both associations were only borderline significant with moderateto-high heterogeneity across studies.

Our cohort finding of a lack of association between total vegetable intake and T2D risk agrees with results from most previous cohort studies ${ }^{(3-11)}$ and meta-analyses ${ }^{(4,14-18)}$, with the only exception being the Shanghai Women's Health Study (SWHS) ${ }^{(13)}$, for which a significant inverse association was reported. Higher green leafy vegetable intake was significantly associated with 10-31\% lower risk of T2D in a Finnish cohort ${ }^{(9)}$, the Chinese SWHS ${ }^{(13)}$, the US Nurses' Health Study (NHS) ${ }^{(3)}$ and the NIH-American Association of Retired Persons Diet and Health Study ${ }^{(7)}$. However, findings from other studies suggested no association $^{(6)}$ or even a direct association with risk of $\mathrm{T} 2 \mathrm{D}^{(7)}$ for green leafy vegetables. Only the SWHS ${ }^{(13)}$ found a significant inverse association between cruciferous vegetable intake and T2D risk. The differences between our results and those of studies that showed inverse associations may be owing to several reasons. Previous studies recruited subjects who participated in health examinations ${ }^{(9)}$, pre-dominantly nonsmoking women ${ }^{(13)}$, nurses ${ }^{(3)}$ or retired persons in the $\mathrm{USA}^{(7)}$. These participants may have been more health conscious than our study population, and their vegetable intake may therefore have been correlated more strongly with other lifestyle factors that are protective for T2D. Although several previous studies statistically adjusted for other lifestyle risk factors, only our cohort and the $\mathrm{NHS}^{(3)}$ accounted for a wide range of dietary confounders. Furthermore, individual vegetables that contributed to specific vegetable groups varied substantially across different studies (online Supplementary Table S3). In the SCHS, green leafy and cruciferous vegetables comprised a variety of individual vegetables, and subjects who had higher intake of total green leafy or cruciferous vegetables may not necessarily have higher intake of individual vegetables that are specifically beneficial for T2D. In addition, although the Egger test did not support publication bias, the funnel plots appeared asymmetric in the meta-analyses of green leafy vegetable intake, suggesting that the possibility of publication bias cannot be excluded.

Previous meta-analyses by Li et al. ${ }^{(15)}$ and Wang et al. ${ }^{(16)}$ each included six cohort studies and suggested a $13 \%(\mathrm{RR}=$ $0.87 ; 95 \%$ CI $0.81,0.93$ ) lower risk of T2D associated with higher green leafy vegetable consumption. Another metaanalysis by Jia et al. ${ }^{(19)}$ included four cohorts and suggested a 
$16 \%(\mathrm{RR}=0.84 ; 95 \% \mathrm{CI} 0.73,0.96)$ lower risk of T2D-associated higher consumption of cruciferous vegetables. Our updated meta-analysis showed slightly weaker associations that were only borderline significant. Moreover, the substantial heterogeneity in results across studies in our meta-analysis indicates that findings for green leafy or cruciferous vegetable consumption on T2D risk have been inconsistent. Although our meta-analyses estimates do not exclude the possibility of moderate benefits of green leafy and cruciferous vegetable consumption and T2D risk, the current evidence for such benefits is not convincing.

Our cohort findings showed suggestive inverse associations for light green and cruciferous vegetable intake in ever-smokers, and significant interaction by sex for preserved vegetable intake. A marginally significant inverse association that was limited to male (but not female) smokers was also observed for cruciferous vegetables in a Japanese cohort ${ }^{(11)}$. Although effect modification of effects of vegetables by smoking or sex hormones cannot be fully ruled out, these observations most likely reflect residual lifestyle confounders that are associated with both smoking dosage or sex and T2D, or chance findings owing to multiple stratified analyses performed.

We found no association between tomato, potato or yellow vegetable intake and risk of T2D after the full adjustment for potential confounders. Among a few studies ${ }^{(6,9,13)}$ that investigated tomato or yellow vegetable intake in relation to risk of T2D, significant inverse associations with both yellow vegetable and tomato intake were observed in the Chinese SWHS, and no associations with yellow vegetable intake in other studies ${ }^{(6,9)}$. Previous results on potato intake and T2D risk have been heterogeneous, ranging from a significant inverse association in the SWHS ${ }^{(47)}$ to no association ${ }^{(5,6,39)}$ or direct associations ${ }^{(9,48)}$ in USA or European studies. In general, potatoes are more likely to be consumed as French fries and eaten in greater amounts in Western populations than in Asians, which may explain these divergent observations. In a report of the three US cohorts ${ }^{(48)}$, the higher T2D risk related to total potato intake was largely driven by the intake of French fries.

In contrast with the lack of association we observed between vegetable consumption and risk of $\mathrm{T} 2 \mathrm{D}$, our previous findings in the SCHS suggested a significant inverse association between a dietary pattern characterised by higher intake of vegetables, fruits and soya foods and T2D risk ${ }^{(49)}$. The potential benefit of this dietary pattern may be explained by higher intake of other plant foods such as unsweetened soya ${ }^{(27)}$ and certain fruits (e.g. apples and grapes) ${ }^{(50)}$ that were inversely associated with T2D risk and/or lower intake of red meat ${ }^{(26)}$ that was directly associated with T2D in our study population.

Strengths of our study included the large sample size, population-based and prospective nature and the broad ranges of the intake of total and specific vegetable groups among cohort participants. Baseline diets were assessed with a semi-quantitative FFQ and only the derived dietary energy and various nutrients, but not vegetables or other whole foods, have been validated. Misclassification of vegetable intakes would likely be non-differential in cohort studies and attenuate a true association towards null. Despite the use of different statistical models and the careful adjustments for various potential confounders, we cannot exclude that residual confounding may have affected our results. Incident diabetes was identified according to participants' self-reports. However, validation studies in our study population indicated that diabetes was accurately reported. Our results may be most generalisable to East Asian populations, and should be confirmed for other ethnic groups.

In this prospective study of ethnic Chinese men and women, total or specific vegetable consumption including consumption of green leafy and cruciferous vegetables was not substantially associated with risk of T2D. In contrast, vegetable consumption was associated with a lower risk of ischaemic heart disease in our cohort $^{(51)}$ and other cohorts ${ }^{(52)}$. Although vegetables are an important part of healthy diets, higher vegetable consumption may not confer the same benefits for T2D risk as have been observed for CVD.

\section{Acknowledgements}

G.-C. C. received an award from the China Scholarship Council. The authors thank Nithya Neelakantan of the National University of Singapore for carefully checking the statistical analyses and reviewing the whole manuscript. The authors express the gratitude to Siew-Hong Low of the National University of Singapore for overseeing the fieldwork of the Singapore Chinese Health Study and Renwei Wang for the development and maintenance of the cohort-study database. Finally, the authors recognise Mimi $\mathrm{C}$. Yu as the founding principal investigator of the Singapore Chinese Health Study.

This study was supported by the National Institutes of Health, USA (NIH R01 CA144034 and UM1 CA182876). W.-P. K. is supported by the National Medical Research Council, Singapore (NMRC/CSA/0055/2013).

Authors' contributions are as follows: G.-C. C. and R. M. v. D. designed the research and developed the analytical plan; G.-C. C. performed the statistical analyses and had primary responsibility for writing the manuscript; W.-P. K., J.-M. Y. and R. M. v. D. directed the study. W.-P. K., J.-M. Y., L.-Q. Q. and R. M. V. D. critically reviewed the manuscript. All authors interpreted the findings, edited the manuscript and approved the final manuscript.

The authors declare that there are no conflicts of interest.

\section{Supplementary material}

For supplementary material/s referred to in this article, please visit https://doi.org/10.1017/S0007114518000119

\section{References}

1. Medina-RemOn A, Kirwan R, Lamuela-Raventos RM, et al. (2016) Dietary patterns and the risk of obesity, type 2 diabetes mellitus, cardiovascular diseases, asthma, and mental health problems. Crit Rev Food Sci Nutr 58, 262-296.

2. Ley SH, Hamdy O, Mohan V, et al. (2014) Prevention and management of type 2 diabetes: dietary components and nutritional strategies. Lancet 383, 1999-2007.

3. Bazzano LA, Li TY, Joshipura KJ, et al. (2008) Intake of fruit, vegetables, and fruit juices and risk of diabetes in women. Diabetes Care 31, 1311-1317. 
4. Cooper AJ, Forouhi NG, Ye Z, et al. (2012) Fruit and vegetable intake and type 2 diabetes: EPIC-InterAct prospective study and meta-analysis. Eur J Clin Nutr 66, 1082-1092.

5. Hodge AM, English DR, O'Dea K, et al. (2004) Glycemic index and dietary fiber and the risk of type 2 diabetes. Diabetes Care 27, 2701-2706

6. Liu S, Serdula M, Janket SJ, et al. (2004) A prospective study of fruit and vegetable intake and the risk of type 2 diabetes in women. Diabetes Care 27, 2993-2996.

7. Mamluk L, O'Doherty MG, Orfanos P, et al. (2017) Fruit and vegetable intake and risk of incident of type 2 diabetes: results from the consortium on health and ageing network of cohorts in Europe and the United States (CHANCES). Eur J Clin Nutr 71, 83-91.

8. Meyer KA, Kushi LH, Jacobs DR Jr., et al. (2000) Carbohydrates, dietary fiber, and incident type 2 diabetes in older women. Am J Clin Nutr 71, 921-930.

9. Montonen J, Jarvinen R, Heliovaara M, et al. (2005) Food consumption and the incidence of type II diabetes mellitus. Eur J Clin Nutr 59, 441-448.

10. Mursu J, Virtanen JK, Tuomainen TP, et al. (2014) Intake of fruit, berries, and vegetables and risk of type 2 diabetes in Finnish men: the Kuopio Ischaemic Heart Disease Risk Factor Study. Am J Clin Nutr 99, 328-333.

11. Kurotani K, Nanri A, Goto A, et al. (2013) Vegetable and fruit intake and risk of type 2 diabetes: Japan Public Health Center-based Prospective Study. Br J Nutr 109, $709-717$.

12. Cooper AJ, Sharp SJ, Lentjes MA, et al. (2012) A prospective study of the association between quantity and variety of fruit and vegetable intake and incident type 2 diabetes. Diabetes Care 35, 1293-1300.

13. Villegas R, Shu XO, Gao YT, et al. (2008) Vegetable but not fruit consumption reduces the risk of type 2 diabetes in Chinese women. J Nutr 138, 574-580.

14. Carter P, Gray LJ, Troughton J, et al. (2010) Fruit and vegetable intake and incidence of type 2 diabetes mellitus: systematic review and meta-analysis. BMJ 341, c 4229.

15. Li M, Fan Y, Zhang X, et al. (2014) Fruit and vegetable intake and risk of type 2 diabetes mellitus: meta-analysis of prospective cohort studies. BMJ Open 4, e005497.

16. Wang PY, Fang JC, Gao ZH, et al. (2016) Higher intake of fruits, vegetables or their fiber reduces the risk of type 2 diabetes: A meta-analysis. J Diabetes Investig 7, 56-69.

17. Wu Y, Zhang D, Jiang X, et al. (2015) Fruit and vegetable consumption and risk of type 2 diabetes mellitus: a doseresponse meta-analysis of prospective cohort studies. Nutr Metab Cardiovasc Dis 25, 140-147.

18. Schwingshackl L, Hoffmann G, Lampousi AM, et al. (2017) Food groups and risk of type 2 diabetes mellitus: a systematic review and meta-analysis of prospective studies. Eur $J$ Epidemiol 32, 363-375.

19. Jia X, Zhong L, Song Y, et al. (2016) Consumption of citrus and cruciferous vegetables with incident type 2 diabetes mellitus based on a meta-analysis of prospective study. Prim Care Diabetes 10, 272-280.

20. Dong JY, Xun P, He K, et al. (2011) Magnesium intake and risk of type 2 diabetes: meta-analysis of prospective cohort studies. Diabetes Care 34, 2116-2122.

21. Veronese N, Watutantrige-Fernando S, Luchini C, et al. (2016) Effect of magnesium supplementation on glucose metabolism in people with or at risk of diabetes: a systematic review and meta-analysis of double-blind randomized controlled trials. Eur J Clin Nutr 70, 1354-1359.

22. Hankin JH, Stram DO, Arakawa K, et al. (2001) Singapore Chinese Health Study: development, validation, and calibration of the quantitative food frequency questionnaire. Nutr Cancer 39, 187-195.

23. Odegaard AO, Koh WP, Arakawa K, et al. (2010) Soft drink and juice consumption and risk of physician-diagnosed incident type 2 diabetes: the Singapore Chinese Health Study. Am J Epidemiol 171, 701-708.

24. Odegaard AO, Pereira MA, Koh WP, et al. (2008) Coffee, tea, and incident type 2 diabetes: the Singapore Chinese Health Study. Am J Clin Nutr 88, 979-985.

25. Willett WC, Howe GR \& Kushi LH (1997) Adjustment for total energy intake in epidemiologic studies. Am J Clin Nutr $\mathbf{6 5}$, 1220S-1228S discussion 1229S-1231S.

26. Talaei M, Wang YL, Yuan JM, et al. (2017) Meat, dietary heme iron and risk of type 2 diabetes: The Singapore Chinese Health Study. Am J Epidemiol 186, 824-833.

27. Mueller NT, Odegaard AO, Gross MD, et al. (2012) Soy intake and risk of type 2 diabetes in Chinese Singaporeans [corrected]. Eur J Nutr 51, 1033-1040.

28. Brunner EJ, Mosdol A, Witte DR, et al. (2008) Dietary patterns and 15-y risks of major coronary events, diabetes, and mortality. Am J Clin Nutr 87, 1414-1421.

29. Erber E, Hopping BN, Grandinetti A, et al. (2010) Dietary patterns and risk for diabetes: the multiethnic cohort. Diabetes Care 33, 532-538.

30. Nettleton JA, Steffen LM, Ni H, et al. (2008) Dietary patterns and risk of incident type 2 diabetes in the MultiEthnic Study of Atherosclerosis (MESA). Diabetes Care 31, $1777-1782$

31. Pastorino S, Richards M, Pierce M, et al. (2016) A high-fat, high-glycaemic index, low-fibre dietary pattern is prospectively associated with type 2 diabetes in a British birth cohort. BrJ Nutr 115, 1632-1642.

32. Satija A, Bhupathiraju SN, Rimm EB, et al. (2016) Plant-based dietary patterns and incidence of type 2 diabetes in US men and women: results from three prospective cohort studies. PLoS Med 13, e1002039.

33. Yu D, Zhang X, Xiang YB, et al. (2014) Adherence to dietary guidelines and mortality: a report from prospective cohort studies of 134,000 Chinese adults in urban Shanghai. Am J Clin Nutr 100, 693-700.

34. Elwood P, Galante J, Pickering J, et al. (2013) Healthy lifestyles reduce the incidence of chronic diseases and dementia: evidence from the Caerphilly cohort study. PLOS ONE 8, e81877.

35. Ford ES \& Mokdad AH (2001) Fruit and vegetable consumption and diabetes mellitus incidence among U.S. adults. Prev Med 32, 33-39.

36. Mandalazi E, Drake I, Wirfält E, et al. (2016) A high diet quality based on dietary recommendations is not associated with lower incidence of type 2 diabetes in the Malmö Diet and Cancer cohort. Int J Mol Sci 17, 901.

37. Malik VS, Li Y, Tobias DK, et al. (2016) Dietary protein intake and risk of type 2 diabetes in US men and women. $A m J$ Epidemiol 183, 715-728.

38. Weng LC, Lee NJ, Yeh WT, et al. (2012) Lower intake of magnesium and dietary fiber increases the incidence of type 2 diabetes in Taiwanese. J Formos Med Assoc 111, 651-659.

39. von Ruesten A, Feller S, Bergmann MM, et al. (2013) Diet and risk of chronic diseases: results from the first 8 years of followup in the EPIC-Potsdam study. Eur J Clin Nutr 67, 412-419.

40. Wells GA, Shea B, O'Connell D, et al. (2013) The NewcastleOttawa Scale (NOS) for assessing the quality of nonrandomised studies in meta-analyses. http://www.ohri.ca/programs/clinical_ epidemiology/oxford.htm (accessed September 2017).

41. DerSimonian R \& Laird N (1986) Meta-analysis in clinical trials. Control Clin Trials 7, 177-188. 
42. Greenland S \& Longnecker MP (1992) Methods for trend estimation from summarized dose-response data, with applications to meta-analysis. Am J Epidemiol 135, 1301-1309.

43. Orsini N, Bellocco R \& Greenland S (2006) Generalized least squares for trend estimation of summarized dose-response data. Stata J 6, 40-57.

44. Higgins JP \& Thompson SG (2002) Quantifying heterogeneity in a meta-analysis. Stat Med 21, 1539-1558.

45. Egger M, Davey Smith G, Schneider M, et al. (1997) Bias in meta-analysis detected by a simple, graphical test. BMJ $\mathbf{3 1 5}$, 629-634.

46. Lacoppidan SA, Kyro C, Loft S, et al. (2015) Adherence to a healthy Nordic food index is associated with a lower risk of type-2 diabetes - The Danish Diet, Cancer and Health Cohort Study. Nutrients 7, 8633-8644.

47. Villegas R, Liu S, Gao YT, et al. (2007) Prospective study of dietary carbohydrates, glycemic index, glycemic load, and incidence of type 2 diabetes mellitus in middle-aged Chinese women. Arch Intern Med 167, 2310-2316.
48. Muraki I, Rimm EB, Willett WC, et al. (2016) Potato consumption and risk of type 2 diabetes: results from three prospective cohort studies. Diabetes Care 39, 376-384.

49. Odegaard AO, Koh WP, Butler LM, et al. (2011) Dietary patterns and incident type 2 diabetes in Chinese men and women: the Singapore Chinese health study. Diabetes Care 34, 880-885.

50. Alperet DJ, Butler LM, Koh WP, et al. (2017) Influence of temperate, subtropical, and tropical fruit consumption on risk of type 2 diabetes in an Asian population. Am J Clin Nutr $\mathbf{1 0 5}$, $736-745$.

51. Rebello SA, Koh H, Chen C, et al. (2014) Amount, type, and sources of carbohydrates in relation to ischemic heart disease mortality in a Chinese population: a prospective cohort study. Am J Clin Nutr 100, 53-64.

52. Aune D, Giovannucci E, Boffetta P, et al. (2017) Fruit and vegetable intake and the risk of cardiovascular disease, total cancer and all-cause mortality-a systematic review and doseresponse meta-analysis of prospective studies. Int J Epidemiol 46, 1029-1056. 